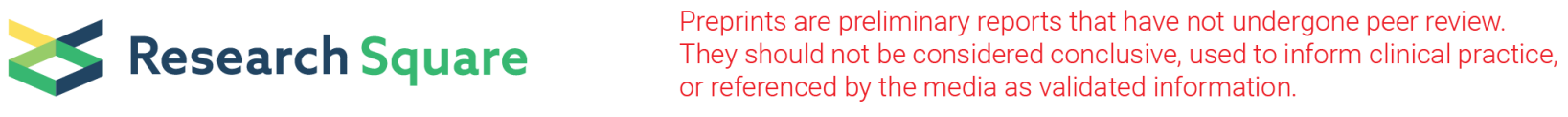

\title{
Does the Mixture of Species change the C:N:P Ecological Stoichiometric Characteristics of fine Roots? A Case Study of Cupressus Funebris Mixed Forest
}

\author{
Wenchun $\mathrm{He}$ \\ Sichuan Agricultural University \\ Yang Wang \\ Sichuan Agricultural University \\ Xiaochen Wen \\ Sichuan Agricultural University \\ Yu Wang \\ Sichuan Agricultural University \\ Baoru Xiao \\ Puyang Academy of Forestry Sciences \\ Gang Chen \\ Sichuan Agricultural University \\ Kuangji Zhao \\ Sichuan Agricultural University \\ Xianwei Li \\ Sichuan Agricultural University \\ chuan fan ( $\square$ fanchuan@sicau.edu.cn ) \\ Sichuan Agricultural University
}

\section{Research}

Keywords: Cupressus funebris, Koelreuteria paniculata, Toona sinensis, mixed forest, fine root ecological stoichiometric, soil physical and chemical properties

Posted Date: May 7th, 2021

DOI: https://doi.org/10.21203/rs.3.rs-473216/v1

License: (c) (i) This work is licensed under a Creative Commons Attribution 4.0 International License. Read Full License 


\section{Abstract}

The growth of fine roots of trees is affected by environmental changes and biological factors. At present, there have been many researches on the physiological plasticity of fine roots caused by environmental changes, but there are still few studies on the influence of biological factors on fine roots. This paper focused on the contents of carbon $(\mathrm{C})$, nitrogen $(\mathrm{N})$, and phosphorus $(\mathrm{P})$, and their ecological stoichiometric ratios in different root orders of Cupressus funebris fine roots in 11 mixed stands with Koelreuteria paniculate or Toona sinensis at different ratios, and the effects of soil physical and chemical properties on the root chemical properties. It aimed to provide new insights into the fine-root nutrient distribution pattern and the transformation or reconstruction of low-efficiency pure forests from the standpoint of forest types. The results showed that: soil pH, and the content of available nitrogen (SAN), available phosphorus (SAP) and available potassium (SAK) differed significantly in the tested mixed forest stands. No significant differences in carbon content of fine roots were observed in different mixed stands. The content of nitrogen and phosphorus in fine roots in mixed forests showed heterogeneity. Species mixing changed the $\mathrm{C} / \mathrm{N}, \mathrm{C} / \mathrm{P}$ and N/P of the $C$. funebris compared the pure stands. The " $T$. sinensis $+C$. funebris" forest alleviated the limitation of the lack of phosphorus on fine roots of $C$. funebris on. The principal component analysis showed that mixed stands of " $T$. sinensis $+C$. funebris" had the highest comprehensive score at ratio of "3:1". Thus, our results recommended the adoption of $T$. sinensis, especially at $75 \%$, to reconstruct the lowefficiency pure $C$. funebris forest.

\section{Introduction}

As many problems, such as low productivity, poor ecological functions, and serious pests and diseases, has been observed for the large area of concentrated and contiguous pure $C$. funebris forests in the hilly area of central Sichuan, (Marino and Onda, 2011), native tree species have been adopted as the companion tree species to build mixed forests to enhance the efficiency of forest land, maintain and protect the biodiversity and the stability of the ecosystem in this region (Zhou et al. 2019). Mixed forest is a plant community composed of different species, and the coexistence of species on a local scale is an important aspect for the mechanism research of community construction and biodiversity maintenance (Henning et al., 2016; Thomas et al., 2018). There are two hypotheses for the species coexistence theory which insists that there are differences among species, Average Fitness Difference (AFD) (HilleRisLambers et al., 2012) and Niche Difference (ND) (Andrew et al., 2017). The former emphasizes the regional equality of average fitness among coexisting species. The latter refers to factors that avoid or buffer the elimination of competition, and achieve stable coexistence through niche differentiation and trade-offs. Previous studies on species coexistence tended to qualitatively describe differences in relative fitness and niche differentiation through theoretical models. It is not only difficult to quantify the differences in species' ecological strategies and ecological functions, but also lacks other relevant information for explaining the mechanisms of biodiversity maintenance .

As plant functional traits are easy to determine, can characterize qualitative and quantitative indicators such as species' adaptation strategies for the environmental and physiological processes, and reflect the advantages of plants' adaptability to the surrounding environment and resource utilization efficiency (Martina et al., 2020), they have been introduced into the study of species coexistence. The C, N and P content of organisms and their ecological stoichiometric characteristics are one of the plant functional traits that are easy to measure, and are closely related to community structure, ecosystem stability, and biogeochemical cycles (James et al., 2009). Some scholars have investigated the soil $\mathrm{C}, \mathrm{N}$ and $\mathrm{P}$, and ecological stoichiometric ratios of different tree species in different regions (such as subalpine, tropical, cold temperate, etc.) (Wang et al., 2018; Michael et al., 2017; Yang et al. 2014; Feng et al., 2017). However, there are few reports on the relationship between ecological stoichiometric ratios and soil C, N or P of different stands under the same main tree species. In addition, can mixed forests change their stability and adopt new survival strategies and adaptability? For lake ecosystems and herbaceous plants, the stoichiometry of bacteria and multicellular animals is considered to have absolute homeostasis, but there are few studies on higher plants and no consensus has been reached (Sabine, 2005; Virginia and Peter, 2009). In addition, ecological stoichiometry is closely related to ecological processes, and most of the reported researches focused on the above-ground leaves (Liu et al., 2020; Gong et al., 2018). However, due to the differences in the content and ratio of C, N, and P among organs (Yang and Luo, 2011; Yuan and Chen, 2010), it is not feasible to replace the root system with the content of carbon, nitrogen and phosphorus in leaves.

The root system is the main body of the underground functional traits of plants. In particular, fine roots (diameter $\leq 2 \mathrm{~mm}$ ), as the main organs for plants to absorb, transport and store nutrients and carbohydrates, play a very important role in the nutrient cycle of plants and forest ecosystems (Kyotaro et al., 2017). When the external environment changes, the fine roots are more sensitive than the above-ground organs, and their functional properties are a good indicator for understanding the subtle changes in the environment (Zhou et al., 2017). The root system has a branching structure similar to branches, and different root orders have great differences in morphology and physiological functions (Amandine et al., 2018; Kyotaro et al., 2017; Zhou et al., 2017). Therefore, it is worthy of in-depth discussion to study the differences of the functional properties of fine roots in different root orders.

Present studies mainly paied more attention to the effects of multi-species ecosystems on fine roots (Amandine et al., 2020; Marie et al., 2019), and how mixing affects the content and ratio of $\mathrm{C}, \mathrm{N}$, and $\mathrm{P}$ in fine roots. The mechanism still remains under debate. Therefore,

Page 2/17 
understanding the mechanism of mixed regulation of fine root changes will help scientifically managing low-efficiency plantations. As the most direct living space for roots, soil provides water and mineral elements for plant growth (Cao et al., 2020). At the same time, the growth, death, and turnover of fine roots will also be affected by soil factors (Sawsan et al, 2019). In addition, during plant growth and development, litter and root exudates can also improve certain physical and chemical properties of the soil, thereby changing its growth state, morphology, and physiological plasticity (E. Oleghe et al., 2017). Some studies also showed that there is a strong relationship between fine root nutrients and soil nutrient availability, pH, soil water content, soil bulk density and other soil physical and chemical properties (Dina et al., 2020; Su et al., 2019). Therefore, it is very important to study the relationship between the content and ratio of fine root $C, N, P$ in different $C$. funebris forests, and the physical and chemical properties of soil.

Based on the above questions and that $C$. funebris is one of the most important protection forest tree species selected and bred in this area the "Koelreuteria paniculata $+C$. funebris", "Toona sinensis $+C$. funebris" and the pure $C$. funebris forest in the early stage of construction were employed in this research, with the research methods of plant functional traits and ecological stoichiometry. Therefore, this study explored the response characteristics of $C$. funebris fine roots in the mixed model through the determination of the carbon, nitrogen and phosphorus of $C$. funebris fine roots and the physical and chemical properties of rhizosphere soil, clarified its adaptation strategies to different forest stand environments, which provided a certain theoretical basis and reference value for further understand the underground growth process of different $C$. funebris forest stands, and the construction or reconstruction of $C$. funebris forest stands.

\section{Materials And Methods}

\subsection{Study sites}

The experimental site was located in Chongzhou Forest Farm, Chongzhou, Chengdu City, Sichuan Province, China (103 $38^{\prime} 50^{\prime \prime} \sim 103^{\circ} 38^{\prime} 50^{\prime \prime} \mathrm{E}$, $30^{\circ} 33^{\prime} 30^{\prime}$ ' $30^{\circ} 33^{\prime} 31^{\prime \prime} \mathrm{N}$ ). The region has a subtropical humid monsoon climate, with four distinct seasons, short spring and autumn, long summer and winter, abundant rainfall, less sunshine, and long frost-free period. The annual average temperature is $16.8^{\circ} \mathrm{C}$, average rainfall $1011.3 \mathrm{~mm}$, annual average sunshine duration $994.9 \mathrm{~h}$, and annual average frost-free period $282 \mathrm{~d}$.

\subsection{Plant materials}

The adopted tree spices were $C$. funebris (sapling height $77.0 \pm 1.2 \mathrm{~cm}$, ground diameter $7.76 \pm 0.15 \mathrm{~mm}$ ), $K$. paniculata (seedling height $94.1 \pm$ $1.4 \mathrm{~cm}$, ground diameter $7.40 \pm 0.13 \mathrm{~mm}$ ) and $T$. sinensis (seedling height $68.0 \pm 1.1 \mathrm{~cm}$, ground diameter $6.97 \pm 0.08 \mathrm{~mm}$ ), which were 2-yearold nutrient-cup seedlings. Ground diameter and height of seedlings for a given species were basically similar, and were growing well.

\subsection{Experimental design}

The 11 stands of "K. paniculata + C. funebris", "T. sinensis + C. funebris", and $C$. funebris pure forest built at the end of October 2015 were selected as the research objects. The mixture of " $K$. paniculata $+C$. funebris" at ratios of "1:3", "1:2", "1:1", "2:1" and "3:1" were referred to as $T_{1}$ to $T_{5}$, while " $C$. funebris $+T$. sinensis" as $T_{6}$ to $T_{10}$. C. funebris pure forest was recorded as the control (CK). A total of 33 sample plots (11 treatments $\times 3$ replicates) were set up in this experiment, consisting of 756 C. funebris seedings, $540 \mathrm{~K}$. paniculata seedlings, $540 \mathrm{~T}$. sinensis seedlings, i.e., 1386 seedlings in total (72 seedlings $\times 33$ plots). The area of each plot was $5 \mathrm{~m} \times 5 \mathrm{~m}$, and in order to avoid mutual interference between treatments, a buffer distance of $4 \pm 0.1 \mathrm{~m}$ was set between each plot. The mixed pattern adopted inter-plant mixing to ensure that the roots of the tree species overlap each other when planting, and the soil is solidified during the planting process. The seedlings were pretreated with mechanical soil preparation, manual weeding and watering 3 days before transplantation, and no management treatment was required after transplantation.

\subsection{Sampling and index determination}

The root and soil samples were collected on October 30, 2017. Three $C$. funebris trees were randomly collected from each plot. The complete root system and the associated rhizosphere soil were dug out, and the root system with fine roots scattered in the soil were sealed in a plastic bag. Some rhizosphere soil were sampled and labeled. The samples are brought back to the laboratory in $12 \mathrm{~h}$, and the roots are rinsed with running water. The dead and alive root were distinguished according to the shape, color and elasticity of the roots, and they were placed in another sealed bags and stored at $4^{\circ} \mathrm{C}$. The cryopreserved roots were washed with deionized water at room temperature to remove the surface residues, were graded using the root order grading method (Amandine et al., 2018). In specific, the roots that are farthest from the main root axis of the root system, having no branches, but having root tips, are defined as the first-level root; the mother root of the first-level root is defined as the second-level root; the second-level root is originated from the third-level root, and so on, until the fifth-level root. The born roots without branches on the high-level roots are also classified as first-level roots. For the scattered roots, the root sequence is divided according to its color, shape and degree of lignification. The roots at different root order were put into corresponding vessels, dried in a $65^{\circ} \mathrm{C}$ oven to constant weight, ground and sieved for the determination of $\mathrm{C}, \mathrm{N}$ and $\mathrm{P}$ content. Soil pH, soil organic carbon (SC), soil total nitrogen (SN), soil 
total phosphorus (SP), soil available nitrogen (SAN), soil available phosphorus (SAP) and soil available potassium (SAK) were also measured at the same time.

The $\mathrm{pH}$ of the soil is determined by the glass electrode method (the water-to-soil ratio is 1:2.5), the SC was determined by the potassium dichromate oxidation-external heating method, the SN was determined by the Kjeldahl method, and the SP was determined by the Kjeldahl method. Sodium hydroxide fusion-molybdenum-antimony colorimetric method was used for determination, the SAN is determined by alkaline hydrolysis diffusion method, the SAP is determined by sodium bicarbonate extraction-molybdenum-antimony colorimetric method, and the SAK is leached with neutral ammonium acetate Extraction-atomic absorption spectrophotometry determination.

\subsection{Statistical analysis}

Microsoft Excel 2007 was used to manage, sort and calculate the data; SPSS 20.0 was used for data statistics. The effect of tree species, mixing ratio, orders and their interactions on the $C$. funebris fine root $\mathrm{C}, \mathrm{N}, \mathrm{P}$ concentration and ecological stoichiometric ratio were analyzed with Three-way ANOVA. Furthermore, the data of C, N, P concentration and stoichiometric ratio of the fine roots of $C$. funebris of $1 \sim 5$-order under different tree species or different ratios were analyzed by One-way ANOVA, followed by multiple comparison of Duncan ( $P \otimes 0.05$ ). Considering the growth of seedlings, the root system is concentrated on the surface of the soil, the physical and chemical properties of the surface rhizosphere soil and the content of C, N, P and their ratios in fine roots were selected for correlation analysis. Principal component analysis was used to obtain the comprehensive index. Sigmaplot 12.5 was used for figure drawing.

\section{Results}

3.1 Soil physical and chemical properties of different forest stands

The introduction of $K$. paniculata or $T$. sinensis into the $C$. funebris forests significantly reduced the pH of the rhizosphere soil $(P<0.05)$, but the differences between mixed forests were not significant $(P>0.05)$ (Table 1). There was no significant differences in SC or SN in different forest stands $(P>0.05)$. In addition, there was no significant differences for SP or SK between mixed forests $(P>0.05)$, but they were significantly higher than those in pure $C$. funebris forests $(P<0.05)$. Mixing significantly increased the available components such as $S A N$, SAP and SAK $(P<0.05)$. In mixed forests, as the proportion of $C$. funebris decreased, SAN, SAP and SAK increased in a high extend. Finally, under the same ratio, $T$. sinensis was more conducive to increasing SAN, SAP and SAK in the mixed forest .

\subsection{C, N and P content and stoichiometric ratio in fine roots of $C$. funebris}

The Two-way ANOVA showed that the fine roots chemical content and stoichiometric ratio of $C$. funebris were significantly influenced under mixing species, mixing ratios, root order and their interaction effects $(P<0.05)$, except that the fine root $\mathrm{N}$ was not affected under the interaction of root order and tree species $(P>0.05)$ (Table 2). That is to say, mixed tree species could affect the content and ratio of $\mathrm{C}, \mathrm{N}, \mathrm{P}$ in fine roots of $C$. funebris.

The fine root $\mathrm{C}$ content of $C$. funebris did not differ among the mixed treatments $(P>0.05)$, but they were all significantly lower than that of pure $C$. funebris forests $(P<0.05)$ (Figure $1 \mathrm{~A}$ ). The fine root $\mathrm{N}$ content of $C$. funebris showed a significant difference among different forest stands $(P<0.05)$ (Figure 1B). The $\mathrm{N}$ content of $1 \sim 4$-order fine roots under $\mathrm{T}_{1}$ treatment showed the highest $(P \otimes 0.05)$, and the $\mathrm{N}$ content of $\mathrm{T}_{8}$ treatment was lower than that of pure forest, but the difference was not significant $(P>0.05)$ (Figure 1B). The change of fine root $\mathrm{P}$ content in mixed $C$. funebris forest showed a heterogeneous trend and was not always higher than that of pure forest (Figure 1C). However, there is a significant difference in fine root $\mathrm{P}$ content between " $K$. paniculata $+C$. funebris" and " $T$. sinensis $+C$. funebris" (Figure $1 C$ ). In general, " $T$. sinensis $+C$. funebris" was higher than "K. paniculata $+C$. funebris", and the $P$ content of $1 \sim 5$-order fine roots under $T_{10}$ showed the highest (Figure 1C).

Fine root C/N, C/P and N/P were all affected by the mixing forest models (Figure 2A, 2B, 2C). The C/N of $1 \sim 5$-order fine roots of the mixed forests were higher than those of pure $C$. funebris forests except for the $T 1$ treatment (Figure $2 A$ ). The fine root $C / P$ in $T_{2}, T_{4}$, and $T_{5}$ treatments was higher than that of pure forest, while the other treatments were lower than those of pure forest (Figure $2 \mathrm{~B}$ ). Overall, $\mathrm{T}_{4}$ treatment had the highest C/P for fine roots (Figure 2B). The fine root N/P of "K. paniculata + C. funebris" were between 13.95 and 24.51, and "T. sinensis $+C$. funebris" between 6.60 and 11.51 (Figure $2 \mathrm{C}$ ).

3.3 Correlation analysis between fine root C, N, P content and stoichiometric ratio of soil physical and chemical properties

There were varying degrees of correlation between the content of $\mathrm{C}, \mathrm{N}$, and $\mathrm{P}$ in fine roots of $C$. funebris and their stoichiometric ratios, and the physical and chemical properties of rhizosphere soil (Table 3). Fine root $\mathrm{C}$ was significantly positively correlated with soil pH $(P<0.01)$, but significantly negatively correlated with SAN, SAP and SAK $(P<0.01)$ (Table 3). Fine root N was significantly negatively correlated with SAN, SAP and SAK (P凶0.05) (Table 3). Fine root C/P was significantly negatively correlated with soil pH, SAP and SAK $(P<0.05)($ Table 3$)$.

Page $4 / 17$ 
3.4 Principal component analysis of the concentration of fine root C, N, P content and its stoichiometric ratio and soil physical and chemical properties

The characteristic indexes of $C$. funebris fine roots (fine root $\mathrm{C}, \mathrm{N}, \mathrm{P}, \mathrm{C} / \mathrm{N}, \mathrm{C} / \mathrm{P}$ and N/P) and soil physical and chemical properties (pH, SC, SN, SP, SK, SAN, SAP, SAK), 14 indicators in total, were adopted for principal component analysis. Four principal component variables were extracted, and the cumulative contribution rate reached $79.681 \%$, which contained sufficient information for most of the original data to meet the requirements of principal component analysis (Table 4). These 4 principal components can be used to analyze the fine root characteristics and soil physical and chemical properties of $C$. funebris under 11 different forests.

Maximum Variance Method was used to rotate the load of each factor, so that the coefficients in the matrix are differentiated from 0-1, which makes it easier to analyze the connotation of the principal components, i.e., the rotated principal component matrix (Table 5). In component 1 , fine root $\mathrm{N}$ and fine root $\mathrm{C} / \mathrm{N}$ contributed the largest load, and fine root $\mathrm{N}$ contribution was negative. In component 2, pH and SAP showed the largest and consistent load. In component 3, fine root $\mathrm{C}$ and fine root $\mathrm{C} / \mathrm{P}$ had the largest load. SC contributed the largest load to Component 4

The comprehensive evaluation model adopted:

$$
\begin{aligned}
\mathrm{F}=\frac{\lambda_{1}}{\lambda_{1}+\lambda_{2}+\lambda_{3}+\lambda_{4}} \times F_{1}+\frac{\lambda_{2}}{\lambda_{1}+\lambda_{2}+\lambda_{3}+\lambda_{4}} \times F_{2} \\
+\frac{\lambda_{3}}{\lambda_{1}+\lambda_{2}+\lambda_{3}+\lambda_{4}} \times F_{3}+\frac{\lambda_{4}}{\lambda_{1}+\lambda_{2}+\lambda_{3}+\lambda_{4}} \times F_{4}
\end{aligned}
$$

In the formula: $F$ is the comprehensive evaluation value; $\lambda_{1}, \lambda_{2}, \lambda_{3}$ and $\lambda_{4}$ are the characteristic root indexes, and $F_{1}, F_{2}, F_{3}$ and $F_{4}$ are the main component values.

Comprehensive index based on principal component analysis of the rhizosphere soil environment and the characteristic factors of $C$. funebris fine roots under different forest stands was obtained through Table 6 (Table 7). The changes of soil physical and chemical properties and characteristic factors of $C$. funebris fine roots under different forest stands tended to be consistent in the 1 5-order fine roots, which generally increased with the increase of root order. K. paniculata or $T$. sinensis was selected as the associated tree species for $C$. funebris transformation, and the comprehensive index of " $T$. sinensis $+C$. funebris" was higher under the same mixing ration. The comprehensive index of " $T$. sinensis $+C$. funebris" increased with increasing proportion of $T$. sinensis, and the score was the highest under the $T_{10}$ treatment.

\section{Discuss}

4.1 Effect of mixing on soil physical and chemical properties

In this study, the physical and chemical properties of soil under different forest stands were measured. The introduction of $K$. paniculata or $T$. sinensis in the $C$. funebris forest significantly reduced the rhizosphere $\mathrm{pH}$, while the difference between the mixed forest stands was not significant (Table 1). This may be resulted from the coexistence of species that secreted organic acids such as formic acid, acetic acid, and oxalic acid into the soil through roots, dissociating more $\mathrm{H}^{+}$, and lowering the soil $\mathrm{pH}$ to a certain extent (Ma et al., 2020). Indexes such as soil organic carbon and soil total nitrogen were not significantly differed among mixed stands (Table 1), which is similar as the results of study on different stands of beech, fir and spruce by Maike et al. (Maike et al., 2016). But significant differences were observed in the study of forests in North China (Wang et al., 2016), which showed that although fine root turnover is one of the important pathways for soil carbon input, it is unlikely to lead a significant change in a short term due to the huge soil organic carbon and soil total nitrogen storage capacity (Xu et al., 2018). Even in some mature forests, the changes are not obvious (Wang et al., 2017). The total phosphorus and total potassium of the soil in the mixed forest were increased compared to pure $C$. funebris forest (Table 1), indicating that the introduction of mixed tree species has changed the type and quantity of microbes in the rhizosphere soil, and transformed them into forms of inorganic phosphorus compounds and $\mathrm{K}^{+}$that are easily absorbed by plants through ammonification and mineralization (Xi et al., 2019). The increased intensities of soil total phosphorus and soil total potassium in the " $K$. paniculata $+C$. funebris" and " $T$. sinensis $+C$. funebris" forest stands differed from each other (Table 1), which may be due to the different interaction modes between species and the different sensitivity of receptors (Ding et al., 2018), thus showing that $T$. sinensis is more suitable for the mixed forests of $C$. funebris. In the mixed forest, the SAN, SAP and SAK had all been improved (Table 1). Three possible reasons might be used to explain this: firstly, the organic acids and protons secreted from the roots of the mixed forest increase the solubility of insoluble nutrients in the soil through acidification or complexation(Li et al., 2007). Secondly, the mixed forest secrets more root exudates into the soil, which in turn provides nutrients and energy substances for the soil microorganisms, so that the 
soil microorganisms multiply, combined with the catalysis of soil enzymes, accelerating the decomposition of insoluble nutrients in the soil (Andres et al., 2018). Thirdly, both T. sinensis and K. paniculata are deciduous tree species, and more litter can be returned to the soil, which accelerates the circulation of available nutrients in the soil (Wang et al., 2017). In addition, mixed litter can also accelerate its return efficiency (Lou et al., 2017; Michael et al., 2019).

\subsection{Effect of mixing on the $\mathrm{C}, \mathrm{N}, \mathrm{P}$ content and stoichiometric ratio in fine roots}

$\mathrm{C}, \mathrm{N}$, and $\mathrm{P}$ are the most basic constituent elements of organisms. The essence of biological growth and development is actually the process of regulating the accumulation and relative proportion of these basic elements (James et al., 2009; Michael et al., 2017). Plant roots, especially fine roots, are the main organs for plants to absorb water and nutrients. At the same time, their functional traits also reflect plant adaptation strategies for soil nutrient availability and intraspecific/interspecific competition (Kyotaro et al., 2017; Amandine et al., 2018). Therefore, the study of nutrient elements in fine roots is of great significance to comprehensively understand the recycling of nutrients in the entire forest ecosystem, especially the underground forest ecosystem.

Stand types have significant effects on the N, P and C/N, C/P and N/P of $C$. funebris fine roots (Figure 1A, 1B, 1C, Figure 2A, 2B, 2C), reflecting the profound significance of species mixing for nutrient balance in plants. In this study, it was found that the $C$ content in $1 \sim 5$-order fine roots was different between the mixed treatments, but it was not significant (Figure 1A). This may be because the $C$, as a structural substance, mainly acts as a skeleton in the plant, and its content is affected by the environment, being less influenced by environment and more stable (Alexandra et al., 2016). But the fine root $C$ of $C$. funebris in mixed stands was significantly higher than that in the pure forest $(P<0.05)$, which is similar to the results of Leena et al. (Leena et al., 2019) on mixed forests in northern Europe, which suggested that some of the photosynthetic products were used for identification or defense between plants, resulting in a decrease in the $\mathrm{C}$ content of fine roots. The results of this study on the $\mathrm{N}$ content of fine roots in different $C$. funebris forests were heterogeneous (Figure 1B), indicating that only an appropriate mixing ratio can make the fine roots have higher nutrient accumulation and turnover capabilities than pure forests. In addition, the N element, as a functional substance, is more susceptible to environmental and inter-species changes (Justin et al., 2016). The mixing of $C$. funebris and $K$. paniculata has a certain promotion effect on the $\mathrm{N}$ content at different root orders of $C$. funebris, and the mixing of " $K$. paniculata $+C$. funebris" at ratio of $1: 3$ can maximize the use of $\mathrm{N}$ in the soil by the mixed forest. It can significantly increase the total $\mathrm{N}$ content of the $1 \sim 4$-order fine roots of $C$. funebris. There might be two possible explanations: one is that there is a certain difference in nutrient requirements between species, showing the dislocation of time or nutrient type (Josie and Stephen, 2020); another is that the space utilized by different species have certain differentiation (Andrew et al., 2017). The changes of $P$ content in fine roots of $C$. funebris mixed forest were heterogeneous (Figure 1C). In general, P content of " $T$. sinensis $+C$. funebris" is higher than that of "K. paniculata $+C$. funebris", and the $\mathrm{P}$ content of $1 \sim 5$-order fine roots is the highest under $\mathrm{T}_{10}$ treatment. This may be due to the interactive effect between mixed tree species, which makes the content and distribution of $\mathrm{P}$ element different in pure forest from that in mixed forest (Xavier et al., 2020). At the same time, it may also attribute to the difference of tree species that different tree species have different competitive positions in the mixed forest, and this kind of competition has changed the growth of fine roots of different tree species, resulting in changes in the $\mathrm{P}$ content that can be obtained by the root system, and thus affecting the absorption of P element by fine roots (Wang et al., 2017). In addition, from the point of the classification of fine root orders, the lower roots are attached to the higher roots, which may also be the reason for the heterogeneity of P content between root orders (Chen et al., 2017).

Plant functional traits do not work separately, but can adapt to environmental changes through a series of combinations and trade-offs between traits. Yuan suggested that there were differences in morphology, chemistry and metabolism of fine roots, so there are differences in stoichiometric ratios (Yuan and Han, 2011). Generally speaking, C/N and C/P can usually reflect the absorption and utilization efficiency of N and $\mathrm{P}$ elements by plants. Higher $\mathrm{C} / \mathrm{N}$ and $\mathrm{C} / \mathrm{P}$ have higher $\mathrm{N}$ and $\mathrm{P}$ utilization efficiency, that is, plants has a higher growth rate (Yuan and Han, 2011; Alexandra et al., 2016; Leena et al., 2019). Species mixing does not change the stoichiometry of $C$. funebris fine roots. Contrary to our results, the introduction of mixed tree species changed the early identification of species and interaction effects between species, thereby influencing the growth and development rate. This study found that the $\mathrm{C} / \mathrm{N}$ and $\mathrm{C} / \mathrm{P}$ of mixed forests are not always higher than those of $C$. funebris cypress forests (Figure 2A, 2B), and the interaction between species would be beneficial, neutral, or inhibited (Michaela et al., 2016). At the same time, due to differences in plant root biomass, fine root volume, etc., an excessively high mixing ratio will not only lead to a high root exudates accumulation, but also resulted in more serious compression of living space (Vicente et al., 2019). In addition, the interaction between species and the sensitivity of receptors are different, which could also cause significant differences between different forest stands (Xavier et al., 2020). N and P are the most vulnerable nutrient elements for plants, and their ratio reflects the most direct signal of plant growth restricted by nutrients (Yuan and Han, 2011). It is generally believed that, during the process of plant growth, N/P<14 can be considered as plant growth restricted by $N, 14<N / P<16$ means that plants are both restricted by $N$ and $P$, and $N / P>16$ means plant growth is restricted by $P$ (Yuan and Han, 2011; Michaela et al., 2016). Wang Zhiqiang et al. (Wang et al., 2020) found that the contents of C, N, and P in fine roots of Chinese plants were $448.81 \mathrm{mg} \cdot \mathrm{g}^{-1}, 10.73 \mathrm{mg} \cdot \mathrm{g}^{-1}$, and $0.9 \mathrm{mg} \cdot \mathrm{g}^{-1}$, respectively, while $\mathrm{C} / \mathrm{N}, \mathrm{C} / \mathrm{P}$ and N/P were 41.84, 508.32 and 11.73, respectively. Yuan et al. (Yuan and Han, 2011) also concluded that the global fine root N/P ranged between 13 18. In this study, both C/N and 
$\mathrm{C} / \mathrm{P}$ were lower than these data (Figure 2A, 2B), indicating that the element utilization efficiency of the $C$. funebris root system in this area was low. At the same time, the introduction of $T$. sinensis or $K$. paniculata into the $C$. funebris forest can adjust its restriction on the use of chemical elements (Figure 2C). The fine root N/P of $C$. funebris in " K. paniculata $+C$. funebris" were 13.95 24.51, which is more restricted by the $P$ element. However, the fine root N/P of $C$. funebris in " $T$. sinensi $+C$. funebris" was 6.60 11.51, which was more restricted by the N element. As the hilly area of central Sichuan is extremely deficient in P element (Zhang et al., 2020), choosing T. sinensias the companion tree species of C. funebris can significantly alleviate the $\mathrm{P}$ deficiency limit of $C$. funebris forest. On the other hand, as this area also belongs to the area of high $\mathrm{N}$ deposition (Peng et al., 2020), the growth limitation of $C$. funebris by $\mathrm{N}$ restriction will be alleviated to some extent in the future.

\section{3 the relationship between the $\mathrm{C}, \mathrm{N}, \mathrm{P}$ content and stoichiometric ratio in fine roots and soil physical and chemical properties}

The content and ratio of C, N, P in fine roots not only depend on the dynamic balance of soil supply and its own morphological construction, but also the mutual adaptation and coordination of species. Many previous studies on subtropical and tropical regions have also shown that there is a certain correlation for physical and chemical properties between plant fine roots and soil (Cao et al., 2020; E. Oleghe et al., 2017; Dina et al., 2020). Our research showed that the $\mathrm{C}$ content of fine roots was significantly positively correlated with soil $\mathrm{pH}$ (Table 3 ). The $\mathrm{C}$ content and $\mathrm{N}$ content of fine roots were significantly negatively correlated with SAN, SAP and SAK (Table 3 ). Fine root C/P has a significant negative correlation with soil pH, SAP and SAK (Table 3). That is to say, the distribution of different physiological and functional traits in the growth process of $C$. funebris fine roots under different forest stands was different, and the changes in soil environment also led to differences in adaptation strategies. In addition, principal component analysis was carried out on the soil physical and chemical properties, and fine root characteristic factors in the 11 different $C$. funebris stands. The factors with higher loading in principal component 1 were all fine root characteristic factors (Table 5). The high loading in component 2 was the soil characteristic factor (Table 5). It showed that $C$. funebris fine root nutrient reacted very quick to the introduction of tree species. From the comprehensive analysis index, as the proportion of $C$. funebris decreased (Table 7), the comprehensive index increases. Therefore, it can be concluded the development of $C$. funebris fine roots and the change of rhizosphere soil environment were more significant with the introduction of $T$. sinensis or K. paniculata,

\section{Conclusion}

Mixing changed the $\mathrm{C}, \mathrm{N}, \mathrm{P}$ content and its ecological stoichiometric ratio in $C$. funebris fine roots. Mixing changed the pH, SAN, SAP and SAK, etc., of the rhizosphere soil, thereby changing the nutrient distribution pattern of $C$. funebris fine roots and affecting its growth and development. Different forest stands adopted different survival strategies among root sequences when responding to changes in the soil environment. In comparison, the first three levels of fine roots were more sensitive. Choosing $T$. sinensis as a mixed species of $C$. funebris can alleviate the influence of $C$. funebris fine roots by the $\mathrm{P}$ restriction . In general, the " $T$. sinensis $+C$. funebris" model with a mixing ratio of " $3: 1$ " had the best effect.

\section{Declarations}

Funding-Structure Optimization and Function Enhancement Technology of Artificial Forest Ecosystem in the Middle Sichuan Hills Area, which is the theme of the National Science and Technology Support Plan for the Twelfth Five-Year Plan (2011BAC09B05). "Sustainable forestry management project in Sichuan", "Research and demonstration of sustainable forest management techniques in the low hilly areas of the Sichuan Basin", funded by a loan from the German Government, from the Forestry Department of Sichuan Province (G1403083). Special thanks to Cui Huang for providing constructive comments. We are also grateful to two anonymous reviewers and the corresponding editor for their insightful comments and very helpful suggestions.

Conflicts of Interest- The authors declare that they have no conflict of interest.

Availability of data and material- The data sets supporting the results of this article are included within the article and its additional files.

Code availability- Not applicable.

Authors' Contributions- All authors contributed to the study conception and design. Wenchun He: Methodology, Data curation, Formal analysis, Writing - original draft, Writing - review and editing. Yang Wang: Data curation, Writing - original draft, Writing - review and editing. Xiaochen Wen: Data curation, Writing - original draft. Yu Wang: Data curation, Writing - original draft. Baoru Xiao: Data curation, Writing - original draft. Gang Chen: Writing - review and editing. Kuangji Zhao: Writing - review and editing. Xianwei Li: Writing - review and editing. Chuan Fan: Methodology, Writing - review and editing.

\section{References}


Alexandra J. Wright, Hans de Kroon, Eric J. W. Visser, et al. (2016) Plants are less negatively affected by flooding when growing in species-rich plant communities. New Phytologist, 213(2):645-656.

Amandine Erktan, M. Luke McCormack, Catherine Roumet. (2018) Frontiers in root ecology: recent advances and future challenges. Plant and Soil, 424:1-9.

Amandine Germon, Jean-Paul Laclau, Agnès Robin, et al. (2020) Tamm Review: Deep fine roots in forest ecosystems: Why dig deeper? Forest Ecology and Management, 466:118-135.

Andres Fuentes-Ramirez, Marcia Barrientos, Leonardo Almonacid, et al. (2018) Short-term response of soil microorganisms, nutrients and plant recovery in fire-affected Araucaria araucana forests. Applied Soil Ecology, 131:99-106.

Andrew D. Letten, Po-Ju Ke, Tandashi Fukami. (2017) Linking modern coexistence theory and contemporary niche theory. Ecologival Monographs, 87(2):161-177.

Cao Yang, Li Yanan, Zhang Guangqi, et al. (2020) Fine root C:N:P stoichiometry and its driving factors across forest ecosystems in northwestern China. Science of the Total Envionment, 737:140299.

Chen Hongying, Dong Yufeng, Xu Tan, et al. (2017) Root order-dependent seasonal dynamics in the carbon and nitrogen chemistry of poplar fine roots. New Forests, 48(5):587-607.

Dina in't Zandt, Nyncke J. Hoekstra, Cornelis A.M. Wagemaker, et al. (2020) Local soil legacy effects in a multispecies grassland community are underlain by root foraging and soil nutrient availability. Joumal of Ecology.

Ding Wenli, Clode L. Peta, Clements C. Jonathan, et al. (2018) Sensitivity of different Lupinus species to calcium under a low phosphorus supply. Plant, Cell and Environment, 41(7):1512-1523.

E. Oleghe, M. Naveed, E. M. Baggs, et al. (2017) Broadleaf trees mediate chemically the growth of Chinese fir through root exudates. Plant and Soil, 421:19-30.

Feng Defeng, Bao Weikai, Pang Xueyong. (2017) Consistent profile pattern and spatial variation of soil C/N/P stoichiometric ratios in the subalpine forests. Journal of Soils and Sediments, 17:2054-2065.

Gong Xusheng, Xu Zhiyan, lu Wei, et al. (2018) Spatial Patterns of Leaf Carbon, Nitrogen, and Phosphorus Stoichiometry of Aquatic Macrophytes in the Arid Zone of Northwestern China. Frontiers in Plant Science, 9:1398.

Henning Nottebrock, Baptiste Schmid, Martina Treurnicht, et al. (2016) Coexistence of plant species in a biodiversity hotspot is stabilized by competition but not by seed predation. Oikos, 126(2).

HilleRisLambers J., Adler P.B., Harpole W.S., et al. (2012) Rethinking community assembly through the lens of coexistence theory. Annual Review of Ecology, Evolution, and Systematics, 43:227-248.

James J. Elser, Marcia Kyle, Laura Steger, et al. (2009) Nutrient availability and phytoplankton nutrient limitation across a gradient of atmospheric nitrogen deposition. Ecology, 90(11):3062-3073.

Josie Antonucci Di Carvalho, Stephen A. Wickham. (2020) Does spatiotemporal nutrient variation allow more species to coexist? Oecologia.

Justin P. Wright, Gregory M. Ames, Rachel M. Mitchell. (2016) The more things change, the more they stay the same? When is trait variability important for stability of ecosystem function in a changing environment. Philosophical Transactions of the Royal Society B: Biological Sciences, 371:1694.

Kyotaro Noguchi, Toko Tanikawa, Yoshiyuki Inagaki, et al. (2017) Calculation procedures to estimate fine root production rates in forests using two-dimensional fine root data obtained by the net sheet method. Tree Physiology, 37:697-705.

Leena Finér, Vitali Zverev, Marjo Palviainen, et al. (2019) Variation in fine root biomass along a $1000 \mathrm{~km}$ long latitudinal climatic gradient in mixed boreal forests of North-East Europe. Forest Ecology and Management, 432:649-655.

Li Long, Li Shumin, Sun Jianhao, et al. (2007) Diversity enhances agricultural productivity via rhizosphere phosphorus facilitation on phosphorus-deficient soils. Proceedings of the National Academy of Sciences of the United States of America, 104(27):11192-11196. 
Liu Ji, Wang Yi, Liu Xinliang, et al. (2020) Ecosystem N:P stoichiometric ratios determine the catchment surface water N:P ratio through subsurface hydrological processes. Catena, 194:104740.

Lou Barbe, Vincent Jung, Andreas Prinzing, et al. (2017) Functionally dissimilar neighbors accelerate litter decomposition in two grass species. New Phytologist, 214(3):1092-1102.

Ma Hang, Li Xuedan, Wei Mingyang, et al. (2020) Elucidation of the mechanisms into effects of organic acids on soil fertility, cadmium speciation and ecotoxicity in contaminated soil. Chemosphere, 239:124706.

Maike Cremer, Nils Valentin Kern, Jörg Prietzel. (2016) Soil organic carbon and nitrogen stocks under pure and mixed stands of European beech, Douglas fir and Norway spruce. Forest Ecology and Management, 367:30-40.

Marie J Zwetsloot, Marc Goebel, Alex Paya, et al. (2019) Specific spatio-temporal dynamics of absorptive fine roots in response to neighbor species identity in a mixed beech-spruce forest. Tree Physiology, 39(11):1867-1879.

Marino H, Onda Y. (2011) Response of infiltration capacity to thinning treatment in Japanese cypress plantation. Agu Fall Meeting Abstr. 8(5): 553-566.

Martina Treurnicht, Jörn Pagel, Jeanne Tonnabel, et al. (2020) Functional traits explain the Hutchinsonian niches of plant species. Global Ecology and Biogeography. 29(3):534-545.

Michael Müller, Yvonne Oelmann, Udo Schickhoff, et al. (2017) Himalayan treeline soil and foliar C:N:P stoichiometry indicate nutrient shortage with elevation. Geoderma, 291:21-32.

Michael Steinwandter, Birgit C. Schlick-Steiner, Florian M. Steiner, et al. (2019) One plus one is greater than two: mixing litter types accelerates decomposition of low-quality alpine dwarf shrub litter. Plant and Soil, 438(1-2):405-419.

Michaela Plein,Michael Bode,Melinda L Moir, et al. (2016) Translocation strategies for multiple species depend on interspecific interaction type. Ecological Applications, 26(4):1186-1197.

Peng Yong, Song Siyi, Li Zengyan, et al. (2020) Influences of nitrogen addition and aboveground litter-input manipulations on soil respiration and biochemical properties in a subtropical forest. Soil Biology and Biochemistry, 142:107694.

Sabine Güsewell. (2005) Responses of wetland graminoids to the relative supply of nitrogen and phosphorus. Plant Ecology, $176: 35-55$.

Sawsan Hassan,Paolo Inglese,Luciano Gristina, et al. (2019) Root growth and soil carbon turnover in Opuntia ficus-indica as affected by soil volume availability. European Journal of Agronomy, 105:104-110.

Su Liang, Du Hu, Zeng Fuping, et al. (2019) Soil and fine roots ecological stoichiometry in different vegetation restoration stages in a karst area, southwest China. Joumal of Environmental Management, 252:109694.

Thomas Cordonnier, Georges Kunstler, Benoît Courbaud, et al. (2018) Managing tree species diversity and ecosystem functions through coexistence mechanisms. Annals of Forest Science,75.

Vicente Vives-Peris,Carlos de Ollas,Aurelio Gómez-Cadenas, et al. (2019) Root exudates: from plant to rhizosphere and beyond.Plant Cell Reports, 39(1):3-17.

Virginia Matzek, Peter M. Vitousek. (2009) N:P stoichiometry and protein:RNA ratios in vascular plants: an evaluation of the growth-rate hypothesis. Ecology Letter, 12(8):765-771.

Wang Junjian, Pisani Oliva, Lin H Lisa, et al. (2017) Long-term litter manipulation alters soil organic matter turnover in a temperate deciduous forest. Science of the Total Environment, 607-608:856-875.

Wang Miaomiao, Chen Hongsong, Zhang Wei, et al. (2018) Soil nutrients and stoichiometric ratios as affected by land use and lithology at county scale in a karst area, southwest China. Science of the Total Enviroment, 619/620:1299-1307.

Wang Shuai, Zhuang Qianlai, Wang Qiubing, et al. (2017) Mapping stocks of soil organic carbon and soil total nitrogen in Liaoning Province of China. Geoderma, 305:250-263.

Wang Tian, Kang Fengfeng, Cheng Xiaoqin, et al. (2016) Soil organic carbon and total nitrogen stocks under different land uses in a hilly ecological restoration area of North China. Soil and Tillage Research, 163:176-184.

Page $9 / 17$ 
Wang Xiaoming, Ki Yijia, Song Xiqiang, et al. (2017) Influence of host tree species on isolation and communities of mycorrhizal and endophytic fungi from roots of a tropical epiphytic orchid, Dendrobium sinense (Orchidaceae). Mycorrhiza, 27(7).

Wang Zhiqiang, Lv Shiqi, Song Hui, et al. (2020) Plant type dominates fine-root C:N:P stoichiometry across China: A meta-analysis. Joumal of Biogeography, 47(5):1019-1029.

Xavier Morin, Thomas Damestoy, Maude Toigo. (2020) Using forest gap models and experimental data to explore long-term effects of tree diversity on the productivity of mixed planted forests. Annals of Forest Science, 77:50.

Xi Nianxun, Bloor M.G. Juliette, Wang Yang, et al. (2019) Contribution of conspecific soil microorganisms to tree seedling light responses: Insights from two tropical species with contrasting shade tolerance. Environmental and Experimental Botany, 166.

Xu Shan, Li Ping, Sayer J. Emma, et al. (2018) Initial Soil Organic Matter Content Influences the Storage and Turnover of Litter, Root and Soil Carbon in Grasslands. Ecosystems, 21(7):1377-1389.

Yang Yan, Wang Genxu, Shen Haihua, et al. (2014) Dynamics of carbon and nitrogen accumulation and C:N stoichiometry in a deciduous broadleaf forest of deglaciated terrain in the eastern Tibetan Plateau. Forest Ecology and Management, 312:10-18.

Yang Yuanhe, Luo Yiqi. (2011) Carbon: nitrogen stoichiometry in forest ecosystems during stand development. Global Ecology and Biogeography. 20:354-361.

Yuan Z.Y., Chen Han Y.H., Reich Peter B. (2011) Global-scale latitudinal patterns of plant fine-root nitrogen and phosphorus. Nature Communications, 344(2).

Z. Y. Yuan, Han Y. H. Chen. (2010) Fine Root Biomass, Production, Turnover Rates, and Nutrient Contents in Boreal Forest Ecosystems in Relation to Species, Climate, Fertility, and Stand Age: Literature Review and Meta-Analyses. Critical Reviews in Plant Sciences, 29:204-221.

Zhong Shouqin, Liu Weiping, Ni Chengsheng, et al. (2020) Runoff harvesting engineering and its effects on soil nitrogen and phosphorus conservation in the Sichuan Hilly Basin of China. Agriculture, Ecosystems and Environment, 301.

Zhou Chuifan, Jiang Wuya, Hou Xiaolong, et al. (2017) Morphological plasticity and phosphorus uptake mechanisms of hybrid Eucalyptus roots under spatially heterogeneous phosphorus stress. Journal of Foresty Research, 28(4):713-724.

Zhou Minghua, Wang Xiaoguo, Ke Yun, et al. (2019) Effects of afforestation on soil nitrous oxide emissions in a subtropical montane agricultural landscape: A 3-year field experiment. Agricultural and Forest Meteorolog, 266:221-230.

\section{Tables}

Table1 the soil physical and chemical properties under different forest stands 


\begin{tabular}{|c|c|c|c|c|c|c|c|c|}
\hline Treatment & $\mathrm{pH}$ & $\mathrm{SC}\left(\mathrm{mg} \cdot \mathrm{g}^{-1}\right)$ & $\mathrm{SN}\left(\mathrm{mg} \cdot \mathrm{g}^{-1}\right)$ & $\mathrm{SP}\left(\mathrm{mg} \cdot \mathrm{g}^{-1}\right)$ & $\mathrm{SK}\left(\mathrm{mg} \cdot \mathrm{g}^{-1}\right)$ & SAN $\left(m g \cdot g^{-1}\right)$ & $\mathrm{SAP}\left(\mathrm{mg} \cdot \mathrm{g}^{-1}\right)$ & $\operatorname{SAK}\left(\mathrm{mg} \cdot \mathrm{g}^{-1}\right)$ \\
\hline $\mathrm{T}_{1}$ & $7.66 \pm 0.09^{b}$ & $16.68 \pm 1.04^{a}$ & $1.43 \pm 0.04^{a}$ & $0.84 \pm 0.03^{a}$ & $16.41 \pm 0.26^{\mathrm{ab}}$ & $125.27 \pm 0.99^{e}$ & $43.89 \pm 0.77^{\mathrm{gh}}$ & $66.56 \pm 1.54^{\mathrm{e}}$ \\
\hline $\mathrm{T}_{2}$ & $7.64 \pm 0.05^{b}$ & $16.72 \pm 0.64^{a}$ & $1.43 \pm 0.02^{a}$ & $0.84 \pm 0.03^{a}$ & $16.43 \pm 0.20^{\mathrm{ab}}$ & $126.08 \pm 0.75^{\mathrm{de}}$ & $44.58 \pm 1.62^{f g}$ & $66.86 \pm 1.89^{e}$ \\
\hline $\mathrm{T}_{3}$ & $7.58 \pm 0.04^{b}$ & $16.73 \pm 0.40^{a}$ & $1.43 \pm 0.03^{a}$ & $0.84 \pm 0.01^{a}$ & $16.46 \pm 0.05^{a b}$ & $128.12 \pm 1.81^{d}$ & $45.86 \pm 0.33^{\mathrm{efg}}$ & $67.13 \pm 1.69^{e}$ \\
\hline $\mathrm{T}_{4}$ & $7.66 \pm 0.04^{b}$ & $16.79 \pm 0.43^{a}$ & $1.43 \pm 0.03^{a}$ & $0.85 \pm 0.01^{a}$ & $16.56 \pm 0.06^{a}$ & $134.23 \pm 2.17^{c}$ & $47.40 \pm 1.99^{\mathrm{cde}}$ & $69.37 \pm 0.96^{c}$ \\
\hline $\mathrm{T}_{5}$ & $7.62 \pm 0.05^{b}$ & $16.96 \pm 0.66^{a}$ & $1.45 \pm 0.01^{a}$ & $0.85 \pm 0.02^{a}$ & $16.61 \pm 0.15^{a}$ & $143.83 \pm 1.83^{a}$ & $49.19 \pm 1.62^{b c}$ & $70.68 \pm 1.24^{b c}$ \\
\hline $\mathrm{T}_{6}$ & $7.60 \pm 0.06^{b}$ & $16.48 \pm 0.75^{a}$ & $1.43 \pm 0.01^{a}$ & $0.84 \pm 0.02^{a}$ & $16.37 \pm 0.15^{\mathrm{ab}}$ & $131.76 \pm 1.34^{\mathrm{c}}$ & $46.60 \pm 0.92^{\text {def }}$ & $69.58 \pm 1.25^{c}$ \\
\hline $\mathrm{T}_{7}$ & $7.57 \pm 0.06^{b}$ & $16.49 \pm 0.88^{a}$ & $1.43 \pm 0.01^{a}$ & $0.84 \pm 0.01^{a}$ & $16.37 \pm 0.10^{\mathrm{ab}}$ & $131.91 \pm 1.43^{c}$ & $47.36 \pm 1.37^{\mathrm{cde}}$ & $70.10 \pm 1.47^{c}$ \\
\hline $\mathrm{T}_{8}$ & $7.63 \pm 0.06^{b}$ & $16.56 \pm 0.71^{a}$ & $1.44 \pm 0.02^{a}$ & $0.84 \pm 0.01^{a}$ & $16.44 \pm 0.17^{a b}$ & $133.41 \pm 0.70^{c}$ & $48.55 \pm 1.68^{b c}$ & $71.09 \pm 0.52^{b c}$ \\
\hline $\mathrm{T}_{9}$ & $7.62 \pm 0.03^{b}$ & $16.62 \pm 0.84^{a}$ & $1.44 \pm 0.01^{a}$ & $0.85 \pm 0.00^{a}$ & $16.51 \pm 0.11^{\mathrm{ab}}$ & $139.2 \pm 1.09^{b}$ & $50.17 \pm 1.21^{b}$ & $72.42 \pm 0.77^{a b}$ \\
\hline $\mathrm{T}_{10}$ & $7.66 \pm 0.02^{b}$ & $16.74 \pm 0.44^{a}$ & $1.45 \pm 0.03^{a}$ & $0.86 \pm 0.01^{a}$ & $16.58 \pm 0.07^{a}$ & $143.68 \pm 0.64^{a}$ & $53.91 \pm 1.35^{a}$ & $73.72 \pm 0.86^{a b}$ \\
\hline CK & $7.78 \pm 0.00^{a}$ & $16.27 \pm 0.00^{a}$ & $1.42 \pm 0.00^{\mathrm{a}}$ & $0.83 \pm 0.00^{a}$ & $16.26 \pm 0.00^{b}$ & $126.9 \pm 2.28^{\mathrm{de}}$ & $42.11 \pm 0.36^{h}$ & $62.09 \pm 0.44^{f}$ \\
\hline
\end{tabular}

NOTE: pH, SC, SN, SP, SK, SAN, SAP, SAK means soil pH, soil organic carbon, soil total nitrogen, soil total phosphorus, soil total potassium, soil alkaline nitrogen, soil available phosphorus, and soil available potassium, respectively. Different lowercase letters in the same column indicate that the relevant indicators between different treatments are significantly different at the 0.05 level.

Table.2 the results of multi-factor analysis of variance of $\mathrm{C}, \mathrm{N}, \mathrm{P}$ content and stoichiometric ratio of fine roots under different stands 


\begin{tabular}{|c|c|c|c|c|c|c|}
\hline source & Type III sum of squares & df & Mean square & $\mathrm{F}$ & Sig. & \\
\hline \multirow[t]{7}{*}{ Fine root carbon } & Root sequence & 368160.867 & 4 & 92040.217 & 4841.861 & .000 \\
\hline & Mixing ratio & 581.573 & 4 & 145.393 & 7.649 & .000 \\
\hline & species & 102.838 & 1 & 102.838 & 5.410 & .022 \\
\hline & Root sequence $\times$ Mixing ratio & 1206.048 & 16 & 75.378 & 3.965 & .000 \\
\hline & Root sequence $\times$ species & 449.768 & 4 & 112.442 & 5.915 & .000 \\
\hline & Mixing ratioxspecies & 1077.215 & 4 & 269.304 & 14.167 & .000 \\
\hline & Root sequence $\times$ Mixing ratio $\times$ species & 1319.380 & 16 & 82.461 & 4.338 & .000 \\
\hline \multirow[t]{7}{*}{ Fine root nitrogen } & Root sequence & 889.845 & 4 & 222.461 & 112.820 & .000 \\
\hline & Mixing ratio & 52.035 & 4 & 13.009 & 6.597 & .000 \\
\hline & species & 226.035 & 1 & 226.035 & 114.632 & .000 \\
\hline & Root sequence $\times$ Mixing ratio & 78.465 & 16 & 4.904 & 2.487 & .003 \\
\hline & Root sequence $\times$ species & 5.878 & 4 & 1.469 & .745 & .563 \\
\hline & Mixing ratioxspecies & 271.945 & 4 & 67.986 & 34.479 & .000 \\
\hline & Root sequence $\times$ Mixing ratio $\times$ species & 165.576 & 16 & 10.348 & 5.248 & .000 \\
\hline \multirow[t]{7}{*}{ Fine root phosphorus } & Root sequence & 7.836 & 4 & 1.959 & 69.547 & .000 \\
\hline & Mixing ratio & 3.224 & 4 & .806 & 28.610 & .000 \\
\hline & species & 10.968 & 1 & 10.968 & 389.351 & .000 \\
\hline & Root sequence $\times$ Mixing ratio & 3.635 & 16 & .227 & 8.064 & .000 \\
\hline & Root sequence $\times$ species & 1.518 & 4 & .379 & 13.471 & .000 \\
\hline & Mixing ratioxspecies & 2.058 & 4 & .514 & 18.264 & .000 \\
\hline & Root sequence $\times$ Mixing ratio $\times$ species & 3.097 & 16 & .194 & 6.871 & .000 \\
\hline \multirow[t]{7}{*}{ Fine root $\mathrm{C} / \mathrm{N}$} & Root sequence & 13833.136 & 4 & 3458.284 & 488.808 & .000 \\
\hline & Mixing ratio & 221.920 & 4 & 55.480 & 7.842 & .000 \\
\hline & species & 880.065 & 1 & 880.065 & 124.392 & .000 \\
\hline & Root sequence $\times$ Mixing ratio & 530.665 & 16 & 33.167 & 4.688 & .000 \\
\hline & Root sequence $\times$ species & 120.760 & 4 & 30.190 & 4.267 & .003 \\
\hline & Mixing ratioxspecies & 622.815 & 4 & 155.704 & 22.008 & .000 \\
\hline & Root sequence $\times$ Mixing ratio $\times$ species & 581.602 & 16 & 36.350 & 5.138 & .000 \\
\hline \multirow[t]{7}{*}{ Fine root $\mathrm{C} / \mathrm{P}$} & Root sequence & 2566506.906 & 4 & 641626.727 & 257.674 & .000 \\
\hline & Mixing ratio & 306055.126 & 4 & 76513.782 & 30.728 & .000 \\
\hline & species & 1253795.637 & 1 & 1253795.637 & 503.518 & .000 \\
\hline & Root sequence $\times$ Mixing ratio & 173868.718 & 16 & 10866.795 & 4.364 & .000 \\
\hline & Root sequence $\times$ species & 201485.670 & 4 & 50371.417 & 20.229 & .000 \\
\hline & Mixing ratioxspecies & 342802.391 & 4 & 85700.598 & 34.417 & .000 \\
\hline & Root sequence $\times$ Mixing ratio $\times$ species & 174471.029 & 16 & 10904.439 & 4.379 & .000 \\
\hline \multirow[t]{3}{*}{ Fine root N/P } & Root sequence & 122.582 & 4 & 30.645 & 13.367 & .000 \\
\hline & Mixing ratio & 274.092 & 4 & 68.523 & 29.888 & .000 \\
\hline & species & 2336.080 & 1 & 2336.080 & 1018.926 & .000 \\
\hline
\end{tabular}

Page 12/17 


\begin{tabular}{llllll|} 
Root sequence $\times$ Mixing ratio & 293.370 & 16 & 18.336 & 7.997 & .000 \\
\hline Root sequence $\times$ species & 94.765 & 4 & 23.691 & 10.333 & .000 \\
\hline Mixing ratioxspecies & 266.671 & 4 & 66.668 & 29.078 & .000 \\
\hline Root sequence $\times$ Mixing ratioxspecies & 215.453 & 16 & 13.466 & 5.873 & .000 \\
\hline
\end{tabular}

Table.3 Correlation coefficients between the concentration and stoichiometric ratio of $\mathrm{C}, \mathrm{N}, \mathrm{P}$ in fine roots of $C$. funebris and the physical and chemical properties of soil

\begin{tabular}{|c|c|c|c|c|c|c|c|c|}
\hline & $\mathrm{pH}$ & SC & $\mathrm{SN}$ & SP & SK & SAN & SAP & SAK \\
\hline $\mathrm{F}_{\mathrm{C}}$ & 0.019 & 0.012 & -0.005 & -0.026 & 0.011 & 0.007 & -0.008 & -0.034 \\
\hline $\mathrm{F}_{\mathrm{N}}$ & 0.146 & 0.065 & -0.065 & -0.137 & 0.036 & $-0.176^{\star}$ & $-0.179^{\star}$ & $-0.233^{* \star}$ \\
\hline $\mathrm{F}_{\mathrm{P}}$ & $-0.191^{*}$ & 0.020 & 0.072 & 0.013 & 0.013 & $0.211^{* *}$ & $0.362^{\star *}$ & $0.357^{\star \star}$ \\
\hline $\mathrm{F}_{\mathrm{C} / \mathrm{N}}$ & -0.085 & -0.050 & 0.039 & 0.062 & -0.044 & 0.085 & 0.101 & 0.132 \\
\hline $\mathrm{F}_{\mathrm{C} / \mathrm{P}}$ & $0.182^{*}$ & 0.014 & -0.033 & 0.035 & 0.047 & -0.082 & $-0.249^{\star \star}$ & $-0.266^{* \star}$ \\
\hline $\mathrm{F}_{\mathrm{N} / \mathrm{P}}$ & $0.298^{* \star}$ & 0.044 & -0.090 & -0.028 & 0.082 & $-0.199^{*}$ & $-0.397^{\star \star}$ & $-0.445^{\star \star}$ \\
\hline
\end{tabular}

NOTE: *and ** represent significant at $\mathrm{P} \otimes 0.05$ and 0.01 , respectively.

Table.4 Interpretation of fine root characteristic factors and total variance of soil physical and chemical properties under different forest stands

\begin{tabular}{|lllll|}
\hline \multirow{2}{*}{ component } & \multicolumn{3}{l}{ Initial eigenvalue } & Extract the sum of squares and load \\
\cline { 2 - 5 } & total & Variance $\%$ & accumulation $\%$ & total \\
\hline 1 & 4.063 & 29.022 & 29.022 & 4.063 \\
\hline 2 & 3.396 & 24.256 & 53.278 & 3.396 \\
\hline 4 & 2.026 & 14.473 & 67.751 & 2.026 \\
\hline 5 & 1.670 & 11.930 & 79.681 & 1.670 \\
\hline 6 & 0.836 & 5.969 & 85.650 & \\
\hline 7 & 0.561 & 4.007 & 89.656 & \\
\hline 8 & 0.424 & 3.028 & 92.684 & \\
\hline 9 & 0.337 & 2.406 & 95.090 & \\
\hline 10 & 0.248 & 1.770 & 96.860 & \\
\hline 11 & 0.182 & 1.303 & 98.163 & \\
\hline 12 & 0.124 & 0.884 & 99.047 & \\
\hline 13 & 0.080 & 0.570 & 99.617 & \\
\hline 14 & 0.037 & 0.266 & 99.883 & \\
\hline
\end{tabular}

Table.5 Rotated component matrix 


\begin{tabular}{|lllll|}
\hline & \multicolumn{5}{l}{ component } \\
\cline { 2 - 5 } & 1 & 2 & 3 & 4 \\
\hline Fine root carbon & -0.188 & -0.152 & 0.925 & 0.045 \\
\hline Fine root nitrogen & -0.915 & -0.154 & 0.107 & 0.037 \\
\hline Fine root C/N & 0.978 & 0.060 & 0.011 & -0.020 \\
\hline Fine root C/P & 0.567 & -0.066 & 0.785 & 0.033 \\
\hline Soil pH & 0.125 & 0.772 & -0.411 & 0.231 \\
\hline Soil carbon & -0.029 & -0.127 & -0.014 & 0.837 \\
\hline Soil available phosphorus & 0.077 & 0.815 & -0.335 & 0.268 \\
\hline
\end{tabular}

Extraction method: principal component analysis method.

Rotation method: Orthogonal rotation method with Kaiser standardization.

a.the rotation converges after 6 iterations.

Table. 6 the coefficient matrix of fine root characteristic factors and soil physical and chemical properties score function under different forest stands

\begin{tabular}{|lllll|}
\hline & \multicolumn{5}{l}{ component } \\
\cline { 2 - 5 } & 1 & 2 & 3 & 4 \\
\hline Fine root carbon & -0.132 & 0.047 & 0.375 & 0.058 \\
\hline Fine root nitrogen & -0.313 & -0.006 & 0.102 & 0.040 \\
\hline Fine root C/N & 0.330 & -0.023 & -0.069 & -0.019 \\
\hline Fine root C/P & 0.133 & 0.028 & 0.266 & 0.038 \\
\hline Soil pH & 0.036 & 0.225 & -0.087 & 0.015 \\
\hline Soil carbon & -0.004 & -0.148 & -0.001 & 0.426 \\
\hline Soil available phosphorus & 0.012 & 0.248 & -0.047 & 0.030 \\
\hline
\end{tabular}

Table.7 Principal component analysis comprehensive index of rhizosphere soil environment and $C$. funebris fine root characteristic factors under different forest stands 


\begin{tabular}{|c|c|c|c|c|c|c|}
\hline Treatment & Root sequence & $\mathrm{F} 1$ & F2 & F3 & F4 & $\mathrm{F}$ \\
\hline \multirow[t]{5}{*}{$\mathrm{T}_{1}$} & 1 & 0.33 & -2.24 & 0.34 & 0.02 & -0.50 \\
\hline & 2 & 0.12 & -1.92 & 0.48 & 0.09 & -0.44 \\
\hline & 3 & -0.10 & -1.33 & 0.47 & 0.09 & -0.34 \\
\hline & 4 & -0.31 & -1.15 & 0.68 & 0.19 & -0.31 \\
\hline & 5 & -0.95 & 1.03 & 0.31 & 0.02 & 0.03 \\
\hline \multirow[t]{5}{*}{$\mathrm{T}_{2}$} & 1 & 0.23 & -1.41 & 0.01 & -0.15 & -0.37 \\
\hline & 2 & 0.05 & -0.99 & 0.03 & -0.14 & -0.30 \\
\hline & 3 & -0.27 & 0.06 & -0.13 & -0.21 & -0.13 \\
\hline & 4 & -0.81 & 1.00 & 0.14 & -0.09 & 0.02 \\
\hline & 5 & -1.34 & 1.74 & 0.52 & 0.08 & 0.15 \\
\hline \multirow[t]{5}{*}{$\mathrm{T}_{3}$} & 1 & 0.05 & -1.31 & -0.11 & -0.27 & -0.44 \\
\hline & 2 & -0.23 & -0.77 & 0.00 & -0.22 & -0.35 \\
\hline & 3 & -0.44 & -0.49 & 0.18 & -0.14 & -0.30 \\
\hline & 4 & -0.88 & 0.45 & 0.27 & -0.10 & -0.15 \\
\hline & 5 & -1.47 & 1.68 & 0.44 & -0.04 & 0.05 \\
\hline \multirow[t]{5}{*}{$\mathrm{T}_{4}$} & 1 & 0.63 & -0.82 & -0.07 & -0.07 & -0.04 \\
\hline & 2 & 0.44 & -0.31 & -0.07 & -0.07 & 0.04 \\
\hline & 3 & 0.14 & -0.09 & 0.27 & 0.08 & 0.08 \\
\hline & 4 & -0.53 & 0.64 & 0.91 & 0.37 & 0.22 \\
\hline & 5 & -1.07 & 1.71 & 1.09 & 0.45 & 0.39 \\
\hline \multirow[t]{5}{*}{$\mathrm{T}_{5}$} & 1 & 0.75 & -0.89 & -0.03 & -0.16 & -0.03 \\
\hline & 2 & 0.43 & -0.47 & 0.21 & -0.04 & 0.05 \\
\hline & 3 & 0.21 & -0.36 & 0.50 & 0.09 & 0.07 \\
\hline & 4 & -0.51 & 0.64 & 1.04 & 0.33 & 0.25 \\
\hline & 5 & -1.02 & 2.47 & 0.66 & 0.14 & 0.52 \\
\hline \multirow[t]{5}{*}{$\mathrm{T}_{6}$} & 1 & 0.17 & -0.29 & -0.81 & -0.37 & -0.23 \\
\hline & 2 & 0.33 & -0.39 & -1.02 & -0.46 & -0.25 \\
\hline & 3 & 0.04 & -0.10 & -0.74 & -0.34 & -0.20 \\
\hline & 4 & -0.38 & 0.53 & -0.46 & -0.22 & -0.09 \\
\hline & 5 & -1.05 & 1.56 & -0.05 & -0.04 & 0.08 \\
\hline \multirow[t]{5}{*}{$\mathrm{T}_{7}$} & 1 & 0.13 & -0.64 & -0.66 & -0.34 & -0.32 \\
\hline & 2 & 0.07 & -0.61 & -0.58 & -0.30 & -0.31 \\
\hline & 3 & -0.19 & -0.45 & -0.26 & -0.15 & -0.28 \\
\hline & 4 & -0.39 & -0.15 & -0.13 & -0.09 & -0.23 \\
\hline & 5 & -1.15 & 2.25 & -0.49 & -0.30 & 0.13 \\
\hline \multirow[t]{3}{*}{$\mathrm{T}_{8}$} & 1 & 0.82 & -1.90 & 0.06 & 0.12 & -0.25 \\
\hline & 2 & 0.60 & -0.71 & -0.35 & -0.06 & -0.07 \\
\hline & 3 & 0.41 & -0.23 & -0.35 & -0.06 & 0.01 \\
\hline
\end{tabular}

Page 15/17 


\begin{tabular}{|c|c|c|c|c|c|c|}
\hline & 4 & 0.10 & 0.45 & -0.28 & -0.03 & 0.12 \\
\hline & 5 & -0.59 & 2.09 & -0.25 & -0.04 & 0.37 \\
\hline \multirow[t]{5}{*}{$\mathrm{T}_{9}$} & 1 & 0.86 & -1.16 & -0.16 & 0.03 & -0.06 \\
\hline & 2 & 0.70 & -0.39 & -0.4 & -0.08 & 0.05 \\
\hline & 3 & 0.47 & -0.20 & -0.15 & 0.04 & 0.09 \\
\hline & 4 & 0.16 & 0.20 & 0.10 & 0.16 & 0.16 \\
\hline & 5 & -0.37 & 1.38 & 0.18 & 0.18 & 0.35 \\
\hline \multirow[t]{5}{*}{$\mathrm{T}_{10}$} & 1 & 1.70 & -0.60 & -0.42 & 0.07 & 0.37 \\
\hline & 2 & 1.68 & -0.76 & -0.28 & 0.14 & 0.35 \\
\hline & 3 & 1.41 & 0.17 & -0.44 & 0.07 & 0.49 \\
\hline & 4 & 0.87 & 0.56 & 0.17 & 0.35 & 0.57 \\
\hline & 5 & 0.39 & 2.18 & -0.11 & 0.20 & 0.81 \\
\hline \multirow[t]{5}{*}{ CK } & 1 & 0.54 & -1.72 & 0.13 & 0.33 & -0.25 \\
\hline & 2 & 0.49 & -0.76 & -0.39 & 0.10 & -0.11 \\
\hline & 3 & 0.17 & -0.09 & -0.29 & 0.15 & 0.00 \\
\hline & 4 & -0.45 & 1.19 & -0.12 & 0.22 & 0.21 \\
\hline & 5 & -0.97 & 1.71 & 0.39 & 0.45 & 0.31 \\
\hline
\end{tabular}

Figures

Figure 1A

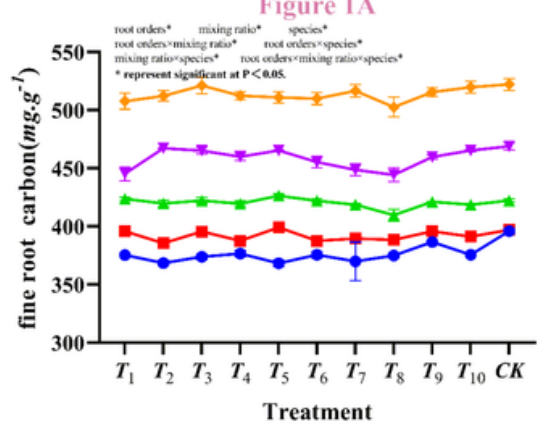

Figure 1B

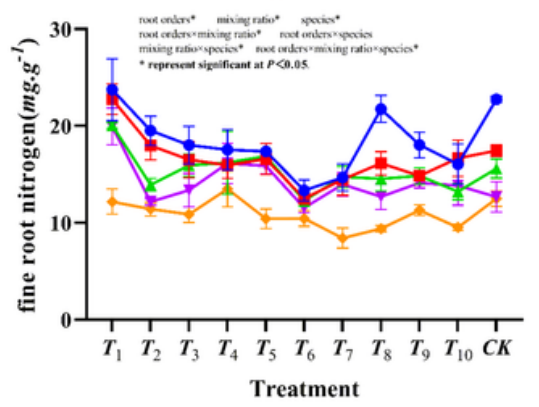

Figure 1C

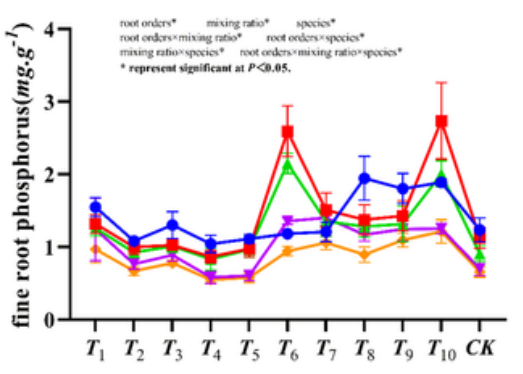

Treatment $\rightarrow$ 1-order

- 2-order

- 3-order

- 4-order

$\rightarrow$ 5-order

\section{Figure 1}

A. The fine root $\mathrm{N}$ content of $\mathrm{C}$. funebris showed a significant difference among different forest stands $(\mathrm{P}<0.05)$. B. The $\mathrm{N}$ content of $1 \sim 4-$ order fine roots under $\mathrm{T} 1$ treatment showed the highest $(\mathrm{P} \otimes 0.05)$, and the $\mathrm{N}$ content of $\mathrm{T} 8$ treatment was lower than that of pure forest, but 
the difference was not significant $(P>0.05)$. C. However, there is a significant difference in fine root $P$ content between "K. paniculata $+C$. funebris" and "T. sinensis + C. funebris"

Figure 2A

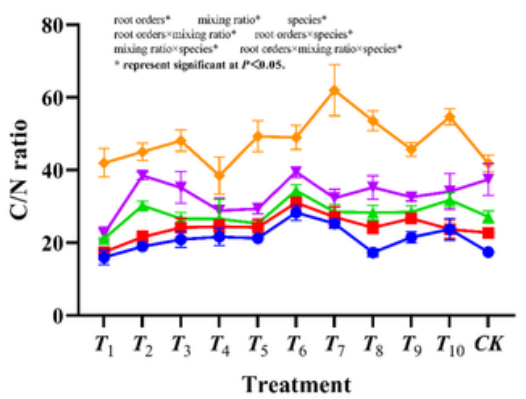

Figure 2B

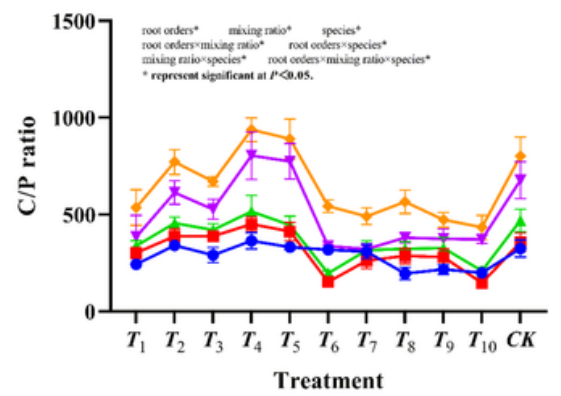

Figure 2C

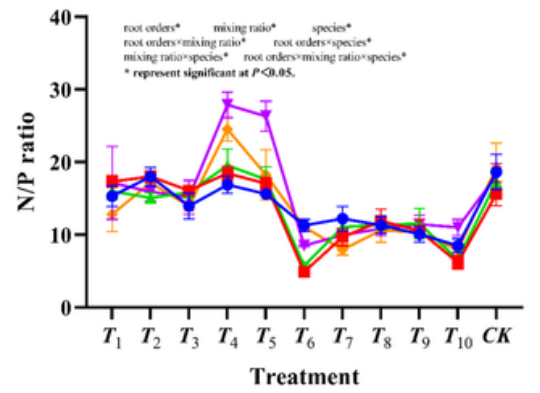

$\rightarrow$ 1-order

$\rightarrow$ 2-order

- 3-order

* 4-order

$\rightarrow$ 5-order

Figure 2

A. The fine root C/P in T2, T4, and T5 treatments was higher than that of pure forest, while the other treatments were lower than those of pure forest. B. Overall, T4 treatment had the highest C/P for fine roots. C. The fine root N/P of C. funebris in "K. paniculata + C. funebris" were 13.95 24.51, which is more restricted by the $\mathrm{P}$ element.

\section{Supplementary Files}

This is a list of supplementary files associated with this preprint. Click to download.

- Heetal.Appendix.docx 